\title{
Cross sectional study: Prevalence of allergic rhinitis among adult asthmatic patients in Kuwait.
}

\author{
Fares Alkhaldy, Adel Abdelhamy, Abdullah Alsaeedi* \\ Department of Internal medicine, Aljahra Hospital 01753, P.O. BOX 40206, Kuwait
}

\begin{abstract}
Background: Allergic rhinitis is prevalent co-morbidity among asthmatic patients. The literature has suggested that it is responsible for poor asthma control. Also, it was found to be an important risk factor for developing of asthma in general population. In Kuwait there are no previous studies that estimated the prevalence of such an association. This study conducted to evaluate the prevalence of allergic rhinitis on adult bronchial asthma in a single center in Kuwait and to examine other common associations.

Material and methods: This is a cross sectional study in a single center to evaluate the prevalence and allergic rhinitis and its effect on asthma management among adults. The data was collected through a distribution of an online questionnaire the score for allergic rhinitis (SFAR) to known asthmatic patients who were diagnosed previously with bronchial asthma in a period of six weeks between January and February 2018. Analyzed, discussed and compared to other relevant study.

Results: 494 asthmatic patients participated in the questionnaire in a period of 6 weeks. $74.7 \%$ were females and $25.3 \%$ was males. $39.7 \%$ of patients were obese and $13 \%$ were smokers. The vast majority of asthmatic patients experienced symptoms of allergic rhinitis in the past 12 months. The most common symptoms experienced were; sneezing (48\%), nose itching (45.5\%), and cough $(35.6 \%)$, moreover, $34.4 \%$ had runny nose. and $20.9 \%$ have had their eyes itching. Interestingly sneezing showed a decreasing prevalence as getting older among males but not females, also runny nose showed biphasic course among age groups. Two thirds $(69.4 \%)$ of the patients were not using any rhinitis medications.

Conclusion: Allergic rhinitis is a common co-morbidity among asthmatic adult patients in our study in Kuwait. The vast majority of patients were not using their rhinitis treatment. Better patient education and adherence to treatment is warranted. Further studies needed to assess the impact of rhinitis treatment on asthma control in Kuwait.
\end{abstract}

Keywords: Allergic rhinitis, Asthmatic patients.

Accepted on June 01, 2018

\section{Introduction}

Asthma and allergic rhinitis (AR) are often coexisting. According to asthma guidelines rhinitis is common in asthmatic patients and occurs in over $75 \%$ in patients with allergic asthma and over $80 \%$ of non-allergic asthma patients [1]. Worldwide epidemiological studies showed AR was prevalent among asthmatics. Between 1983 and 2004 AR was 50\% to $100 \%$ prevalent in adult asthmatic patients in USA and Europe [2]. In Japan, AR was found to be $67.3 \%$ among asthmatic patients [3].

In the Middle East a study conducted in United Arab Emirates, (7\%) of the studied population had an experience of allergic rhinitis [4].

Allergic rhinitis may occur in a period of time before developing asthma [5] and was suggested to be a risk factor in development of bronchial asthma [6]. In addition to the burden of allergic rhinitis on patients with asthma, it can complicate the management of asthma and responsible for poor asthma outcome [7].

In Kuwait there was only one study conducted looking at the prevalence of allergies in general. 3110 students participated in a survey regarding of asthma, allergic rhinitis and eczema.
The age of students was from 13 to 14 years old. They found that the studied population has a moderate prevalence of asthma, allergic rhinitis and eczema in comparison with other countries [8]. No previous studies done in Kuwait to look for how prevalent are AR among adult asthma patients. This study conducted to evaluate the prevalence of allergic rhinitis and its impact on asthma management.

\section{Materials and Methods}

A cross sectional study conducted in a single center (Al-jahra hospital) pulmonary medicine outpatient clinic (8 clinics per week) in a period of six weeks between January and February 2018. Patients were interviewed in the clinic and an online questionnaire the score for allergic rhinitis (SFAR) [9] was distributed among a known adult ( $>18$ years) population that was diagnosed previously with bronchial asthma. Patients were divided in to three age groups 20-35, 35-50, and >50 years old.

Analyzing the data using Microsoft Excel and comparing between two groups of asthmatic patents, those with allergic rhinitis and non-allergic rhinitis. Data were statistically described in terms of frequencies (number of cases) and percentages. Comparison 
Citation: Alkhaldy F, Abdelhamy A, Alsaeedi A. Cross sectional study: Prevalence of allergic rhinitis among adult asthmatic patients in Kuwait. Arch Gen Intern Med. 2018;2(3):32-35. DOI: 10.4066/2591-7951.1000055

between the study groups was done using Chi-square $\left(\chi^{2}\right)$ test. Exact test was used instead when the expected frequency is less than 5. Multivariate logistic regression analysis was used to test for the significant risk factors of each symptom. P values less than 0.05 was considered statistically significant. All statistical calculations were done using computer program IBM SPSS (Statistical Package for the Social Science; IBM Corp, Armonk, NY, USA) release 22 for Microsoft Windows.

Further epidemiological exploring of data conducted to assess the prevalence of other co-morbidities and common associated allergies and triggers.

\section{Results}

\section{Study population}

494 of adult asthmatic patients participated in the questionnaire in a period of 6 weeks. The majority (Tables 1 and 2) of participants were females $74.7 \%$ and $25.3 \%$ were males. $44.3 \%$ and $43.1 \%$ is in age groups $36-50$ years old and $20-35$ respectively. While only $12.6 \%$ of questioned population is over 50 years old. $39.7 \%$ of the population studied was obese, $53.4 \%$ was with normal range BMI, and 6.9\% was under-weight. $34 \%$ of the population was either diagnosed since childhood or more than five years. Other participants' diagnosis date was not available. It is notable that, majority were non-smokers $84.6 \%$, whereas only $13 \%$ of the participants who are smokers, and only $2.4 \%$ were previously smokers. $45.3 \%$ of the patients with no family history of asthma or AR, 20.9\% have both family history of asthma and allergic rhinitis, $16.8 \%$ and $17 \%$ of the population have asthma or allergic rhinitis family history respectively.

Table 1. Characteristics of study population. BMI: Body Mass Index; AR: Allergic Rhinitis; BA: Bronchial Asthma.

\begin{tabular}{|c|c|c|c|c|}
\hline Characteristics & Overall & Women & Men & $p$ value \\
\hline$N$ & $494(100.0 \%)$ & $369(74.7 \%)$ & $125(25.3 \%)$ & \\
\hline \multicolumn{5}{|l|}{ Age group: } \\
\hline - $20-35$ years, $n(\%)$ & $213(43.1)$ & $123(33.3)$ & $90(72.0)$ & $<0.001$ \\
\hline - $\quad 36-50$ years, $n(\%)$ & $219(44.3)$ & $193(52.3)$ & $26(20.8)$ & \\
\hline - $\quad>50$ years, $\mathrm{n}(\%)$ & $62(12.6)$ & $53(14.4)$ & $9(7.2)$ & \\
\hline \multicolumn{5}{|l|}{ BMI group: } \\
\hline - Underweight, n (\%) & $34(6.9)$ & $17(4.6)$ & $17(13.6)$ & $<0.001$ \\
\hline - Normal weight, n (\%) & $264(53.4)$ & $202(54.7)$ & $62(49.6)$ & \\
\hline - Overweight, n (\%) & $196(39.7)$ & $150(40.7)$ & $46(36.8)$ & \\
\hline \multicolumn{5}{|l|}{ Smoking: } \\
\hline $\begin{array}{l}\text { - Smokers/Ex-smokers, } \\
\mathrm{n}(\%)\end{array}$ & $76(15.4)$ & $7(1.9)$ & $69(55.2)$ & $<0.001$ \\
\hline - Non-smokers, n (\%) & $418(84.6)$ & $362(98.1)$ & $56(44.8)$ & \\
\hline Food allergy, n (\%) & $100(20.2)$ & $75(20.3)$ & $25(20.0)$ & 0.938 \\
\hline \multicolumn{5}{|l|}{ Family history: } \\
\hline - $\quad$ AR, n (\%) & $84(17.0)$ & $62(16.8)$ & $22(17.6)$ & 0.117 \\
\hline - $\quad B A, n(\%)$ & $83(16.8)$ & $62(16.8)$ & $21(16.8)$ & \\
\hline - Both, n (\%) & $103(20.9)$ & $86(23.3)$ & $17(13.6)$ & \\
\hline - None, n (\%) & $224(45.3$ & $159(43.1)$ & $65(52.0)$ & \\
\hline Co-morbidities, n (\%) & $113(22.9)$ & $93(25.2)$ & $20(16.0)$ & 0.034 \\
\hline Other allergies, n (\%) & $44(9.0)$ & $34(9.2)$ & $10(8.2)$ & 0.733 \\
\hline Treatment of AR & $151(30.6)$ & $119(32.2)$ & $32(25.6)$ & 0.163 \\
\hline \multicolumn{5}{|l|}{ Medications: } \\
\hline - Antihistaminic, n (\%) & $45(71.4)$ & $38(80.9)$ & $7(43.8)$ & 0.018 \\
\hline - Decongestants, n (\%) & $6(9.5)$ & $3(6.4)$ & $3(18.8)$ & \\
\hline - Steroids, n (\%) & $12(19.0)$ & $6(12.8)$ & $6(37.5)$ & \\
\hline
\end{tabular}

\section{Prevalence of allergic rhinitis symptoms among asthmatics}

In this study (Table 3 and Figures 1,2) sneezing was a common co-association with asthma in $48 \%$ of the population studied $\mathrm{P}=0.6$, and nose itching in $45.5 \% \mathrm{P}=0.6$. Moreover, patients who had cough $35.6 \% \mathrm{P}=0.75$. Similarly, $34.4 \% \mathrm{P}=0.4$ had runny nose and $20.9 \% \mathrm{P}=0.2$ have had eye itching. Only $15.6 \%$ of patients answered was not experiencing AR symptoms. Interestingly as shown in Figure 3 sneezing showed an inverse relationship to age group among males, were sneezing prevalence decreased

Table 2. Patients information.

\begin{tabular}{|c|c|c|c|}
\hline \multicolumn{4}{|c|}{ Patients information } \\
\hline Age & $20-35$ & $36-50$ & $50+$ \\
\hline & $43.1 \%$ & $44.3 \%$ & $12.6 \%$ \\
\hline Gender & Female & Male & Null \\
\hline & $74.7 \%$ & $23.3 \%$ & Null \\
\hline BMI & Underweight & Normal Wight & Overweight \\
\hline & $6.9 \%$ & $53.4 \%$ & $39.7 \%$ \\
\hline
\end{tabular}

Table 3. Prevalence of Rhinitis symptoms according to gender.

\begin{tabular}{|c|c|c|c|c|}
\hline Characteristics & Women & Men & Crude OR (95\%Cl) & p value \\
\hline $\mathrm{N}$ & $369(74.7 \%)$ & $125(25.3 \%)$ & & \\
\hline Runny nose & $107(29.0)$ & $41(32.8)$ & $1.195(0.773,1.848)$ & 0.422 \\
\hline Sneezing & $178(48.2)$ & $57(45.6)$ & $0.899(0.599, .351)$ & 0.61 \\
\hline Cough & $130(35.2)$ & $46(36.8)$ & $1.070(0.702,1.632)$ & 0.751 \\
\hline Nose itching & $144(39.0)$ & $46(36.8)$ & $0.910(0.598,1.384)$ & 0.659 \\
\hline Eye redness & $88(23.8)$ & $23(18.4)$ & $0.720(0.432,1.201)$ & 0.207 \\
\hline No symptoms & $52(14.1)$ & $25(20.0)$ & $1.524(0.899,2.582)$ & 0.116 \\
\hline
\end{tabular}

\section{AR Symptoms}

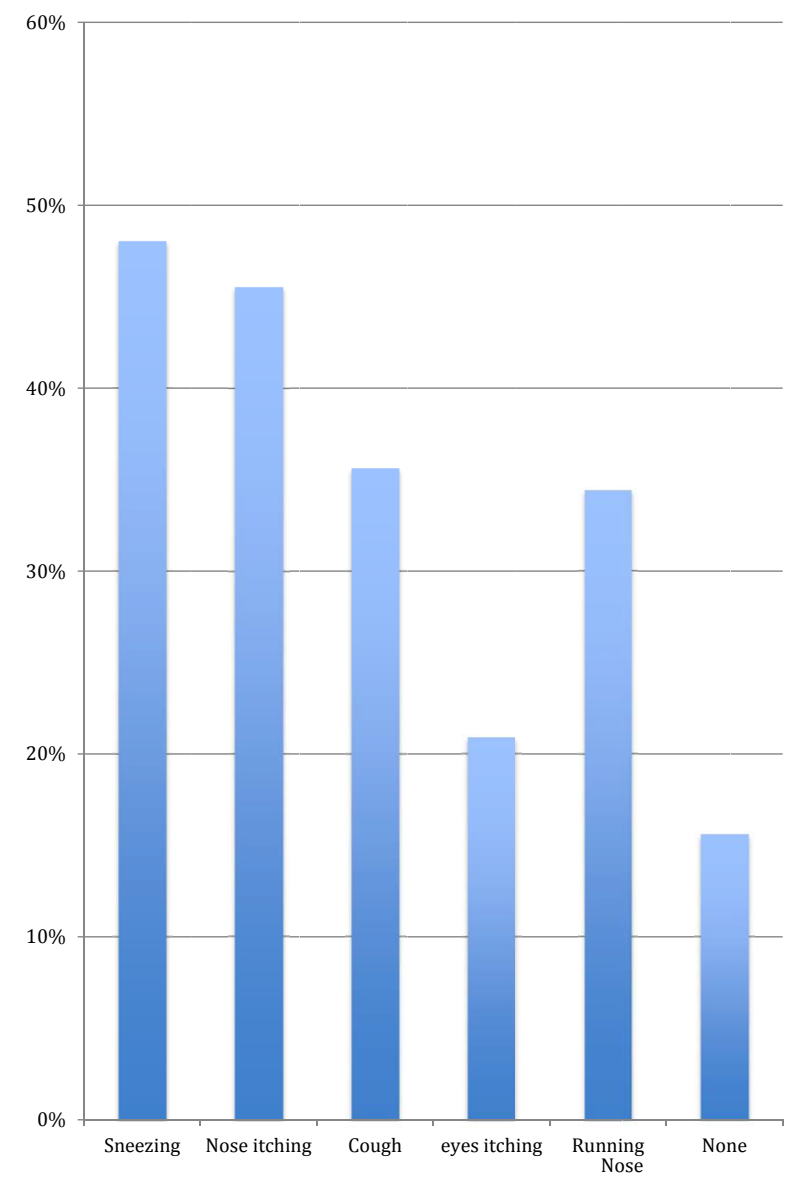

Figure 1. Allergic rhinitis symptoms percentage. 
with aging but this was not for females which showed a biphasic course. Runny nose showed biphasic course among age groups, where it was more common in young (20-35 years) and old ( $>50$ years) with inverse gender relationship as males predominate younger age group and females older age group (Figure 3).

Other association found in this study was $20.2 \%$ reported they have food allergies. $10 \%$ have eczema, and $6.2 \%$ of their allergy triggered by dusts. Antibiotics allergy was reported as well by $4.8 \%$ of patients.

$8.9 \%$ were diabetic and $7.5 \%$ are with hypertension. Sleep apnea was found to be $3 \%$ among patients studied. In relation to pharmacological control of $\mathrm{AR}$, only $30.6 \% \mathrm{P}=0.16$ is on medications.

\section{Discussion}

The study is the first known study to be conducted in Kuwait examining the prevalence of AR symptoms among adult asthmatics. It showed that a great prevalence of AR symptoms in asthmatic patients.

The study shows that the prevalence of different allergic rhinitis symptoms among asthmatic patient are different according to age group and gender, in comparison between runny nose and sneezing there is no significant difference between males and females in different ages in runny nose symptom (Figure 2) but there is significant difference between males and females in different age groups in sneezing specially in 50 years old group (Figure 3). These symptoms of AR was downgraded by many

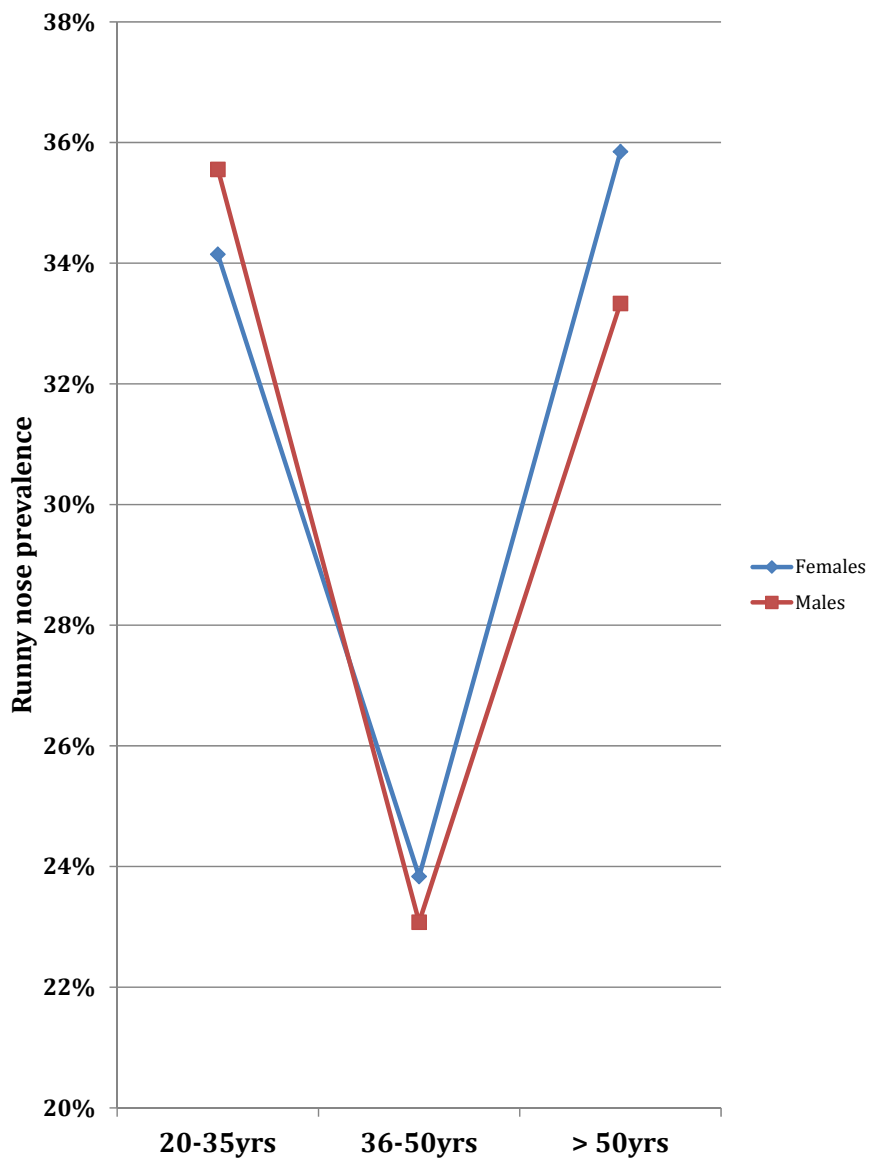

Figure 2. Prevalence of runny nose by age group and gender. patients as only third of them considered active management of AR as approximation of $70 \%$ of responded they do not use any medication regarding the treatment of allergic rhinitis. The literature suggested a strong link between allergic rhinitis and asthma [10]. Based on number of studies, allergic rhinitis is considered as a risk factor for asthma [10]. Both lack of awareness, education and the low severity of symptoms play a significant role in lack of seeking for treatment of allergic rhinitis. Educating the patients and promote its treatment will result in lowering the opportunity of more serious outcome.

Approximately half of the asthmatic patients studied do not have a family history of either asthma or allergic rhinitis. Unfortunately, due to the poor response to the question regarding the specific allergen that patients are allergic to, we could not identify possible environmental allergens in our community beside dust. It is believed that environmental factor play a major role in developing the disease [11]. Education of the disease and its impact on asthmatic patients, their quality of life and the environmental association will increase the awareness and disease prevention [12].

\section{Study Limitations}

The study is a cross sectional study. It has many limitations. Firstly, it studies the prevalence of the disease and the frequency of other related factors. Yet, does not establish causality or identify risk factors. Secondly, it is a retrospective study, which may have a recall bias. Which can be defined

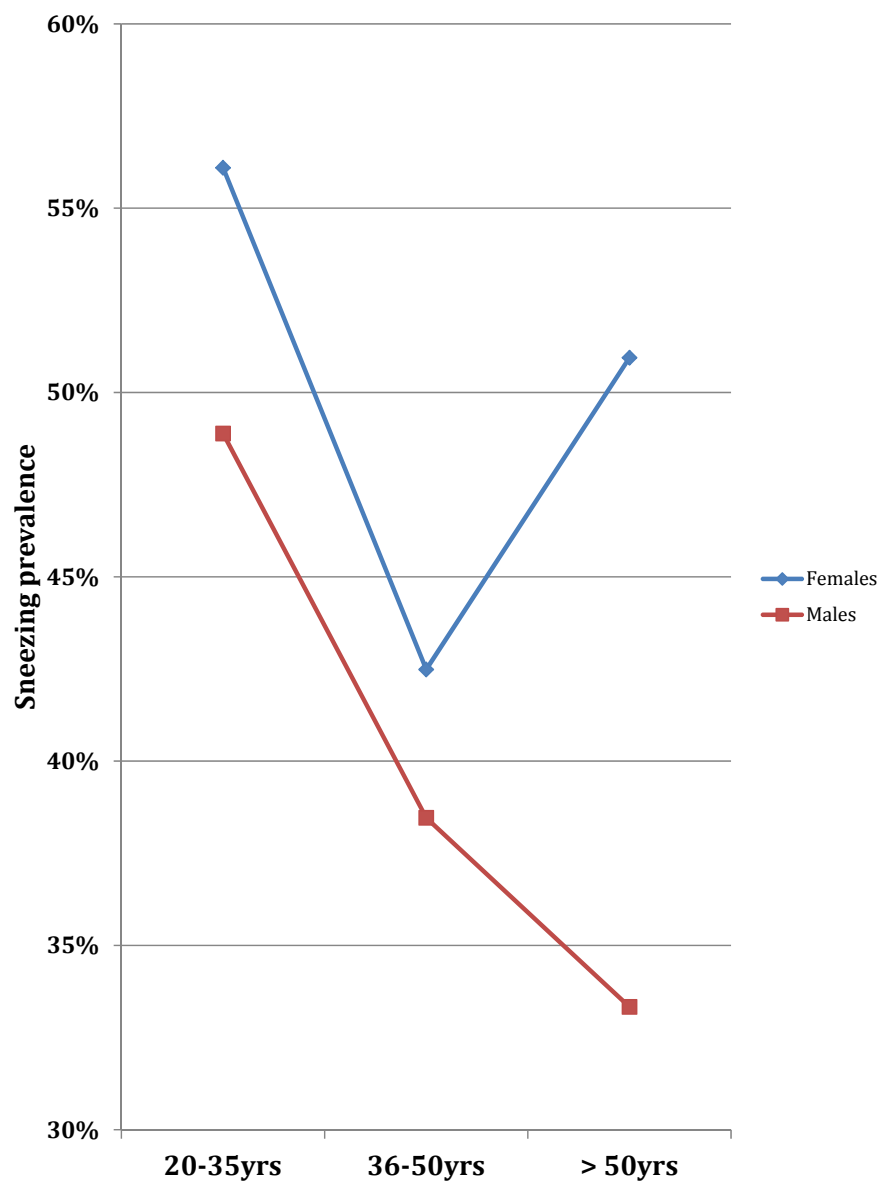

Figure 3. Prevalence of sneezing by age group and gender. 
as alerting the answers due to previously awareness of disorders? However, an appropriate strategy to reduce bias is by decreasing the time from exposure to follow up. Thirdly, the survey carried out in Arabic language as the Kuwait population was targeted to be involved in the study. That may has some language and medical terminology accuracy translations issues. Yet it was possible to reduce the margin of error by comparing the terminology of the study to other studies in the region. For example, the study that conducted in United Arab Emirates regarding allergic rhinitis and pollutants [4]. As both Kuwait and United Arab Emirates share same language, cultrate, demographical constitutes and geographically sharing similar features.

\section{Conclusion}

This is the first known study conducted in Kuwait to assess the prevalence of allergic rhinitis among adult asthmatic patients. Allergic rhinitis is a common co-morbidity among adult asthmatic. The vast majority of patients were not using their rhinitis treatment. Better patient education and adherence to treatment is warranted. Further studies needed to assess the impact of rhinitis treatment on asthma control in Kuwait.

\section{References}

1. Bousquet J, Van Cauwenberge P, Khaltaev N. Allergic rhinitis and its impact on asthma. The J Allergy and Clinical Immunology. 2001;108(5 Suppl):S147-334.

2. Gaugris S, Sazonov-Kocevar V, Thomas M. Burden of concomitant allergic rhinitis in adults with asthma. The Journal of asthma: official journal of the Association for the Care of Asthma. 2006;43:1-7.

3. Ohta K, Bousquet PJ, Aizawa H, et al. Prevalence and impact of rhinitis in asthma. SACRA, a cross-sectional nation-wide study in Japan. Allergy. 2011;66:1287-95.

4. Mahboub B, Al-Hammadi S, Prakash VP, et al. Prevalence and triggers of allergic rhinitis in the United Arab Emirates. The World Allergy Organization J. 2014;7(1):19.
5. Settipane RJ, Hagy GW, Settipane GA. Long-term risk factors for developing asthma and allergic rhinitis: a 23-year follow-up study of college students. Allergy Proceedings: The official Journal of Regional and State Allergy Societies. 1994;15:21-5.

6. Bousquet J, Gaugris S, Kocevar VS, et al. Increased risk of asthma attacks and emergency visits among asthma patients with allergic rhinitis: a subgroup analysis of the investigation of montelukast as a partner agent for complementary therapy. Clinical and Experimental Allergy. 2005;35:723-7.

7. Price D, Zhang Q, Kocevar VS, et al. Effect of a concomitant diagnosis of allergic rhinitis on asthma-related health care use by adults. Clinical and experimental allergy. J British Society for Allergy and Clinical Immunology. 2005;35:282-7.

8. Behbehani NA, Abal A, Syabbalo NC, et al. Prevalence of asthma, allergic rhinitis, and eczema in 13- to 14-year-old children in Kuwait: an ISAAC study. International Study of Asthma and Allergies in Childhood. Annals of allergy, asthma \& immunology: official publication of the American College of Allergy, Asthma, \& Immunology. 2000;85:58-63.

9. Annesi Maesano I, Didier A, Klossek M, et al. The score for allergic rhinitis (SFAR): a simple and valid assessment method in population studies. Allergy. 2002;57:107-14.

10. Tajiri T, Niimi A, Matsumoto H, et al. Prevalence and clinical relevance of allergic rhinitis in patients with classic asthma and cough variant asthma. Respiration; international review of thoracic diseases. 2014;87:211-8.

11. Panzner P, Malkusova I, Vachova M, et al. Bronchial inflammation in seasonal allergic rhinitis with or without asthma in relation to natural exposure to pollen allergens. Allergologia Immunopathologia. 2015;43:3-9.

12. Sinha B, Singla R, Chowdhury R. Allergic Rhinitis: A neglected disease - A community based assessment among adults in Delhi. J Postgraduate Med. 2015;61:169-75.

\section{*Correspondence to:}

Abdullah Alsaeedi
Department of Internal medicine
Aljahra Hospital 01753
P.O. BOX 40206
Kuwait
E-mail: alsaeedi44@hotmail.com

